DOI: http://dx.doi.org/10.11606/issn.1984-4867.v25i1p185-202

\title{
Satisfação dos Clientes Quanto à Qualidade dos Serviços do Terminal Rodoviário de Natal (RN)
}

\author{
Satisfacción de los Clientes en Cuanto la Calidad de los Servicios del Terminal Autobuses \\ de Natal (RN)
}

The Satisfaction of the Clients as to the Quality of Services of the Natal's BusTerminal

$(R N)$

\author{
Alcêdo Pinheiro Galvão ${ }^{1}$ \\ Fabiana Nascimento da $\mathrm{Cruz}^{2}$ \\ Janikelle Alves Faucão ${ }^{3}$
}

\begin{abstract}
Resumo
A qualidade de serviços é uma das principais preocupações dos gestores, fator esse que contribui para satisfação dos clientes. A pesquisa tem como objetivo analisar satisfação quanto à qualidade dos serviços oferecidos pelo Terminal Rodoviário de Natal (RN), na escala SERVPERF. A pesquisa foi fundamentada na revisão da literatura servindo esta como base para compreensão e análise dos resultados. Os dados coletados foram analisados de forma quantitativa, conduzidos à conclusão da aplicabilidade. $\mathrm{O}$ modelo adotado possui cinco dimensões que sugerem uma contribuição direta para a percepção da satisfação geral dos passageiros em relação à Tangibilidade, Confiabilidade, Presteza, Segurança e Empatia, através de vinte e dois itens adaptados ao terminal. A amostra foi constituída com a participação de passageiros que embarcavam no terminal com o intento de se atingir o nível de confiança e a margem de erro tolerável. O resultado da pesquisa sinaliza que as dimensões do modelo proposto contribuem para a satisfação dos passageiros. Os principais problemas identificados foram: confiança na segurança e nas instalações, o comprometimento em solucionar problemas, o esclarecimento de dúvidas e o atendimento cordial aos passageiros. Observou-se através das variáveis de caracterização que as pessoas que mais utilizam à rodoviária, optando por viajar de ônibus, residem no estado, com evidência na cidade de Natal, atribuindo ao terminal à importância não apenas turística, mas um meio que facilita o deslocamento.
\end{abstract}

Palavras-chave: Qualidade de serviços. Satisfação dos passageiros. Modelo SERVPERF.

\footnotetext{
${ }^{1}$ Mestre em Administração pela Universidade Potiguar. Especialista em Gestão dos Recursos Humanos pela Universidade do Estado do Rio Grande do Norte (UERN). Graduado em Adminsitração de Empresas pela Universidade Regional do Rio Grande do Norte. Professor da UERN. Brasil. E-mail: alcedogalvao@gmail.com.

${ }^{2}$ Pós-graduanda em Educação Ambiental e Geografia do Semi-Árido pelo Instituto Federal do Rio Grande do Norte (IFRN). Bacharel em Turismo pela UERN. Brasil. E-mail: fabianacruz83@ hotmail.com.

3. Pós-graduanda em Educação Ambiental e Geografia do Semi-Árido pelo IFRN. Bacharel em Turismo pela UERN. Brasil. E-mail: jani_kelle@hotmail.com.
} 


\title{
Resumen
}

La calidad del servicio es una de las principales preocupaciones de los gestores, factor que contribuye para la satisfacción de los clientes. La pesquisa tiene como objetivo analizar la satisfacción en cuanto la calidad de los servicios ofrecidos por lo Terminal Autobuses de Natal (RN), en la escala SERVPERF. La encuesta fue fundamentada en la revisión de la literatura teniendo la misma como base para el entendimiento y análisis de los resultados. Los datos recogidos fueron analizados de forma cuantitativa, conduciendo a la conclusión de la aplicabilidad. El modelo adoptado tiene cinco dimensiones que sugieren una contribución directa para la percepción de la satisfacción general de los pasajeros en relación a la Tangibilidad, Confiabilidad, Prestación, Seguridad y Empatía, a través de los veinte y dos objetivos adaptados al terminal. La muestra fue constituida con la participación de los pasajeros que embarcaban en el terminal con el intento de alcanzar el nivel de confianza y el margen del error tolerable. El resultado de la pesquisa señaliza que las dimensiones del modelo propuesto contribuyen para la satisfacción de los pasajeros. Los principales problemas identificados fueron: confianza en la seguridad y en las instalaciones, el compromiso en solucionar problemas, el esclarecimiento de las dudas y la atención cordial a los pasajeros. Se observó a través de las variables de caracterización que las personas que más utilizan la estación de autobús, optando por viajar de autobús, residen en el estado, con evidencia en la ciudad del Natal, atribuido a la terminal y la importancia no solo turística, pero un medio que facilita el movimiento.

Palabras-Claves: Calidad de servicio, Satisfacción de los pasajeros. Modelo SERVPERF.

\begin{abstract}
The quality of the services is one of the principals' manager's preoccupations, a factor that contribute for the client's satisfaction. The research has as objective the satisfaction analyses as to the quality of services offered by the Natal's bus terminal (RN), in the scale SERVPERF. The research was crucial in the literature review serving it as base for the compression and results analysis. The data collected was analyzed by a quantitative away, conducted to the conclusion of the applicability. The model adopted has five dimensions that suggest a direct contribution for the general satisfaction's perception of the passengers in relation to the tangibility, reliability, promptitude, security and empathy, by twenty two items adapted to the terminal. The sample was constituted with the participation of the passengers that embarked in the terminal with the intent to achieve the level of trust and a tolerable error margin. The results of the research signalized that the model's dimension proposed contribute to the satisfaction of the passengers. The principals identified problems were: trust in the safety and in the installation, the commitment in solving problems, the clarifying of the doubts and the cordial service to the passengers. It was observed by the variables of the characterization that the persons that utilized more the bus terminal, opting by bus traveling, reside in the state, with evidence in the city of Natal, attributing to the terminal not only the touristic importance, but an away that facilitates the dislocation.
\end{abstract}

Keywords: Quality of service. Passenger's satisfaction. Model SERVPERF. 


\section{Introdução}

O turismo tem se expandido de forma consistente, como um indutor de crescimento econômico nos países em desenvolvimento, tendo em vista os fatores que justificam o turismo, nota-se que para ser turista, uma pessoa precisa se deslocar para um lugar diferente de sua residência, sem que ocorra busca financeira, promovendo interação entre a sociedade e a economia local.

O aumento da mobilidade na sociedade tem se desenvolvido devido a obrigações de trabalho, estudo ou vinculo afetivo, com isso, nem toda viagem pode ser tida como turismo e as pessoas precisam se deslocar sendo uma atividade associada à acessibilidade e consequentemente aos transportes, por isso o presente estudo busca identificar e avaliar a qualidade dos serviços oferecidos pelo Terminal Rodoviário de Natal - Rio Grande do Norte (RN), utilizando a escala SERVPERF.

O Terminal Rodoviário de Natal (RN) possui um papel importante como estação rodoviária para os passageiros, o mesmo serve de apoio à atividade turística e é um meio que beneficia pessoas que moram em uma cidade e trabalham em outra, que estudam em um lugar e possuem outro como moradia, precisando, assim, se deslocar através de um transporte rodoviário.

O estudo objetiva conhecer o perfil socioeconômico do viajante que embarca no Terminal Rodoviário de Natal $(\mathrm{RN})$, verificando a percepção em relação à infraestrutura oferecida, averiguando o nível de satisfação na dimensão confiabilidade, constatando a percepção dos viajantes em relação à presteza na rodoviária, reconhecendo se os usuários sentem-se seguros com os serviços oferecidos e identificar o nível de satisfação em relação ao atendimento oferecido pelo terminal.

Com isso, diante das novas formas de criar meios de transportes devido às novas necessidades decorrentes das evoluções que estão ocorrendo, principalmente a de locomoção que aumentou gradativamente, percebe-se a necessidade de estabelecer um padrão de qualidade nos serviços prestados para se atingir o mínimo de expectativa dos clientes, uma vez que Natal é uma cidade que tem o turismo como uma de suas principais fonte de renda, associada ao fato que será uma das sedes da Copa do Mundo de Futebol FIFA em 2014. Evento este que será uma 
grande oportunidade para o turismo na cidade de Natal e a qualidade dos serviços, por sua vez, é constituída por fatores complexos que necessitam de investigação.

Este artigo está dividido em seis seções, incluindo esta introdução. A segunda seção fornece uma síntese da revisão de literatura sobre redes e alianças estratégicas no turismo e sobre o setor hoteleiro, assim como descreve o arcabouço de análise estratégica relacional adotada. A terceira seção apresenta a metodologia da pesquisa empírica. Nas duas seções seguintes os resultados da pesquisa são apresentados e discutidos, respectivamente. Na sexta e última seção, destacam-se as lições principais da pesquisa e fornecem-se algumas recomendações para investigações futuras.

\section{Referencial Teórico}

\subsection{Qualidade em Serviços}

A qualidade em serviços tem se tornado uma exigência entre os consumidores de serviços, pois não se busca apenas a diferenciação do produto. Muito tem se falado a respeito da qualidade de produtos, serviços e do atendimento ao cliente, a necessidade de sobreviver num mundo cada vez mais competitivo, tem sido vista como um objetivo contínuo para manter a empresa priorizada na lista do cliente, uma vez que o público tem se tornado mais exigente com o mercado.

Para Las Casas (2009, p.89), “qualidade em serviços está ligada à satisfação. Um cliente satisfeito com o prestador de serviços estará percebendo um serviço como de qualidade”.

A satisfação é determinada pela diferença entre as percepções e expectativas do cliente, o consumidor é motivado por sua percepção, onde se busca analisar a prestação de um serviço avaliando se o mesmo possui qualidade, um fator importante quando se busca a satisfação. De acordo com Kotler e Armstrong (2003b, p.130), “percepção é o processo pelo qual uma pessoa seleciona, organiza e interpreta as informações recebidas para formar uma visão significativa do mundo".

A satisfação desempenha um papel particularmente crítico em ramos altamente competitivos, na qual se constata uma enorme diferença entre a fidelidade de consumidores meramente 
satisfeitos com a dos completamente satisfeitos ou encantados. Lovelock e Wright (2001) conceituam a satisfação como sendo uma reação emocional de curto prazo a um desempenho específico.

As organizações para manter ou melhorar os níveis de satisfação precisa descobrir inicialmente o quanto seus atuais clientes estão realmente satisfeitos ou insatisfeitos, sendo essa uma ferramenta que buscará melhorar ou aprimorar a prestação do serviço, criando produtos e serviços de acordo com as necessidades dos clientes,

Os serviços são diferenciados por vários autores e com vários adjetivos, de acordo com Kotler e Armstrong (1998a) serviços é caracterizado como atos, processos e desempenhos, como também todas as atividades econômicas, cujo produto não é físico ou construído. Mas dentre tantos conceitos e definições, a característica que talvez melhor defina serviços é a sua intangibilidade, pois é muito difícil palpar ou tocar um serviço.

Segundo Lovelock e Wright (2001, p.5), “serviço é um ato ou desempenho oferecido por uma parte à outra, o desempenho é essencialmente intangível e normalmente não resulta em propriedade de nenhum dos fatores de produção".

A efetivação de um serviço pode estar ou não ligada a um produto concreto, uma vez que os serviços não podem ser vistos ou experimentados antes de seu uso, porém seu produto pode ser algo visto ou não, e diante disso, os serviços possuem características comuns de um serviço no qual podem ser identificadas:

(1) Serviços são processos de atividades que consistem em atividades ou uma série de atividades. (2) Serviços são, no mínimo até certo ponto, produzidos e consumidos simultaneamente. (3) O cliente participa como coprodutor no processo de produção, pelo menos até certo ponto. (GRÖNROOS, 2009, p.47).

De acordo com Kotler e Armstrong (2003b) as empresas possuem características especiais a serem consideradas em um serviço: a intangibilidade, inseparabilidade, variabilidade e perecibilidade. 
Intangibilidade, os serviços não podem ser vistos, sentidos, tocados ou cheirados antes de sua utilização. Por exemplo: os passageiros que viajam em um transporte rodoviário, possuem somente seu bilhete de passagem e a promessa de que chegarão ao seu destino final.

Inseparabilidade, os serviços não podem ser separados de seus fornecedores, ou seja, os passageiros de um terminal rodoviário não podem ser separados do ônibus. Tanto o usuário precisa do veículo para que o serviço seja concretizado como as empresas de transportes precisam dos passageiros para que uma viagem seja realizada.

Variabilidade, a qualidade do serviço varia de acordo com quem fornece, a prestação de informações em uma plataforma de embarque pode ser realizada de forma objetiva e cortês, enquanto no mesmo local em horários diferentes pode ser efetuada de uma maneira indiferente.

Perecibilidade, os serviços não podem ser armazenados para uso superior, as empresas de transportes rodoviário, no caso o transporte regular, se não venderem todos os assentos, terão que realizar a viagem, independente da quantidade de pessoas embarcada, e uma vez não vendida, não poderão ser armazenados e posteriormente guardados.

Diante das características apresentadas, torna-se claro que os serviços precisam de pessoas para relacionar e fazer o serviço acontecer, ocorrendo um processo simultâneo de produção e consumo, chamado de inseparabilidade, podendo ser variável de acordo com a qualidade oferecida, não sendo possível guardar um serviço uma vez não utilizado, bem como os mesmos não podem ser testados antes de seu uso.

Diante do exposto, é primordial que uma empresa busque a excelência na qualidade dos seus serviços, e quando se fala em transportes, a opinião do cliente em terminais pode ser formada rapidamente com base na simpatia do atendimento e da qualidade dos serviços disponíveis.

A qualidade dos serviços oferecidos pode ser avaliada devido ao crescimento das exigências dos consumidores, com isso os terminais rodoviários precisam prestar serviços de qualidade de forma a satisfazer às necessidades de seus passageiros. Para tanto, a qualidade dos serviços possui importância fundamental para garantir o sucesso e a competitividade existente no mercado. 


\subsection{Modelo de Avaliação de Qualidade (SERVPERF)}

Dentre as diversas ferramentas de avaliação da qualidade do serviço, podemos destacar o modelo SERVQUAL, desenvolvido e aperfeiçoado por Parasuraman et al. (1985). Esse modelo conceitual define que a qualidade é avaliada pelo consumidor na comparação entre as expectativas e a percepção que obteve da performance do serviço.

Para Las Casas (2009, p.92), "todas as ferramentas normalmente utilizadas para avaliar a qualidade podem servir como avaliação interna". Porque quando se fala em qualidade de serviços se faz necessário medir as reações dos clientes.

Zeithaml e Bitner (2005) apud SILVA (2009) afirmam que, em serviços, o valor atribuído à qualidade depende da satisfação por parte do cliente, pois os clientes esperam um serviço de qualidade e após a utilização pode se mostrar satisfeitos ou não. Em Las Casas (2009), o modelo de qualidade é definido:

O Servqual é, portanto, uma proposta para medir a qualidade do serviço com base em uma comparação da expectativa do cliente com a avaliação do serviço recebido. Esse método para determinar a qualidade do serviço é a teoria do hiato ou lacuna (gap theory). Para isso, foi elaborado um questionário que contém, na primeira parte, uma indicação do nível de serviços esperados pelos respondentes em determinada indústria. Numa outra parte do questionário, os serviços prestados são avaliados. (LAS CASAS, 2009, p.94).

O modelo SERVQUAL possui dois conjuntos, um que corresponde a 22 itens para avaliar expectativas e outro com 22 itens para mensurar as percepções, através de 5 dimensões da qualidade, assim caracterizadas:

-Tangibilidade: avaliação das instalações, equipamentos, aspectos de higiene e aparência dos funcionários.

-Confiabilidade: capacidade de um prestador de serviços realizar um serviço prometido de forma confiável e correta.

-Presteza: capacidade de prestar o serviço com boa vontade e prontidão.

-Segurança: capacidade do prestador do serviço prestar serviços com confiança através do conhecimento e cortesia. 
-Empatia: cuidados e atenção individualizados aos clientes, colocando-se no lugar do consumidor com o objetivo de prestar serviços adaptados às necessidades do cliente.

Entretanto, o modelo SERVQUAL, sofreu algumas críticas quanto a sua metodologia devido à inconsistência dos resultados por não atender a todos os setores de serviço. Com isso, surgiu um novo modelo de avaliação chamado SERVPERF, desenvolvido pelos autores Cronin e Taylor (1992), a partir das criticas a escala SERVQUAL. A nova escala proposta, parte do principio de que a percepção que os clientes têm da qualidade do serviço baseia-se numa atitude pré-concebida acerca do serviço.

Em Mattozo et al. (2012), o modelo SERVPERF, traduzido numa escala, destina-se a medir o desempenho global da qualidade do serviço. O mesmo utiliza as mesmas questões e dimensões do SERVQUAL, com 22 (vinte e duas) questões distribuídas em tangibilidade, confiabilidade, presteza, segurança e empatia e sugere que a qualidade deve ser aferida apenas com base nas percepções dos consumidores acerca da performance do prestador do serviço.

Silva et al. (2009) salienta que Cronin e Taylor (1992) realizaram uma pesquisa empírica em quatro segmentos do setor de serviços para comparar o modelo SERVQUAL e o SERVPERF. Após a aplicação de técnicas que analisam a confiabilidade e validade dos instrumentos, eles chegaram à conclusão de que a escala SERVPERF apresenta maior confiabilidade para mensurar a qualidade de serviço que a escala $S E R V Q U A L$. Além disso, pode-se afirmar que ela é mais eficiente, pois reduz em $50 \%$ o número de itens que devem ser avaliados pelos respondentes, o que proporciona uma maior credibilidade das respostas. Eles também observaram que a escala $S E R V P E R F$ explica uma parcela maior da variação em qualidade de serviço do que a escala $S E R V Q U A L$ e, através da análise de modelos estruturais, sustentaram a superioridade teórica da escala SERVPERF, pois somente este modelo confirmou-se consistentemente.

\subsection{Terminal Rodoviário de Natal (RN)}

O Terminal Rodoviário de Natal, localizado na zona oeste da cidade de Natal (RN), no bairro Cidade da Esperança, é a principal estação rodoviária do estado. A construção da rodoviária na Cidade da Esperança teve como um dos motivos, de acordo com Souza, questões políticas que buscavam forçar um desenvolvimento na área, com a construção do empreendimento e 
“ao longo dos três governos Maia - Tarcísio, Lavosier e José Agripino, de março de 1975 até maio de 1986, a Cidade da Esperança recebeu vários benefícios". (SOUZA, 2008, p. 739) Porém, esse não foi o único motivo, o fato mais relevante foi à transferência para um local que proporcionasse uma melhor estrutura física aos guichês de passagens, bem como infraestrutura adequada aos passageiros.

O terminal rodoviário é ponto de embarque e desembarque de passageiros de ônibus provenientes de outros estados ou do interior do estado do Rio Grande do Norte e conta com linhas regulares para as seguintes cidades/estados brasileiros: Maceió (Alagoas); Aracaju (Sergipe); Salvador (Bahia); Fortaleza (Ceará); Brasília (Distrito Federal); Goiânia (Goiás); São Luís (Maranhão); Belo Horizonte (Minas Gerais); São Paulo (São Paulo); Belém (Pará); João Pessoa (Paraíba). Além de possuir linhas interestaduais, o terminal atende aos passageiros do interior do estado do Rio Grande do Norte.

Desde a sua inauguração, o Terminal Rodoviário de Natal nunca havia passado por uma reforma que contribuísse para modernização e conservação do mesmo, sua administração era de competência do Departamento de Estradas e Rodagens (DER), sendo aberta uma licitação pública para que a mesma passasse a ser gerenciada por concessionária e desde junho de 2008, a rodoviária passou a ser administrada pela Sociedade Campinense (SOCICAM).

A SOCICAM foi à empresa vencedora da concorrência de licitação pública de nº 091/2077SIN, aberta pelo Governo do Estado, pelo contrato que tem duração de 30 anos, a empresa ficou responsável por administrar e executar a reforma do terminal.

A rodoviária de Natal, para melhor atender a seus usuários, dispõe do serviço de Informações Turísticas que funciona no Balcão de Informações, onde se encontra um funcionário da Secretaria Municipal de Turismo. Através desse serviço os usuários podem tirar diversas dúvidas relacionadas ao Terminal Rodoviário e à cidade de Natal. Os passageiros também podem contar com os serviços: achados e perdidos, acessibilidade para atender aos portadores de necessidades especiais, loja de artesanato, lanchonete, correios, banca de revista, lotérica, caixas eletrônicos, estacionamento, guarda volumes, sanitários femininos e masculinos, serviço de táxi, telefone público, empresas de ônibus que atuam no terminal com a venda de passagens e Outros Serviços. 
A reforma do Terminal Rodoviário teve início em 2010 e ao seu término contará com 32 guichês para bilheterias, 35 lojas para comércio e uma âncora, praça de alimentação, novos banheiros com fraldários e espaços familiares, adequados às normas de acessibilidade, além disso, o estacionamento passará de 150 para 200 vagas após a reforma, segundo informações fornecidas pela administração do terminal.

\section{Métodos}

O estudo trata-se de uma pesquisa aplicada, pois objetiva gerar conhecimentos para aplicação prática com base na análise da satisfação do cliente em relação à qualidade dos serviços oferecidos pelo Terminal Rodoviário de Natal (RN), segundo Vergara (2010, p. 43) "A pesquisa aplicada é fundamentalmente motivada pela necessidade de resolver problemas concretos, mais imediatos, ou não".

Em relação aos objetivos, é uma pesquisa explicativa, buscando ampliar o embasamento teórico do tema proposto, conforme Gil (2007, p.44), "este é o tipo de pesquisa que mais aprofunda o conhecimento da realidade, porque explica a razão, o porquê das coisas".

O modelo conceitual proposto foi identificado como o mais adequado para a aferição do nível de satisfação no que diz respeito à qualidade dos serviços prestados na Rodoviária de Natal. A figura 1 apresenta as dimensões e os atributos considerados no modelo conceitual proposto para a pesquisa, com 22 itens adaptados ao local de pesquisa. 


\section{Tangibilidade}

-Existência de equipamentos modernos -Instalações físicas atrativas: banheiro, praça de alimentação, estacionamento, iluminação, assentos de embarque;

-Vestimenta e aparência dos colaboradores;

- Conservação de guichês, restaurantes e lojas.

\section{Segurança}

-Segurança nos serviços oferecidos;

-Disponibilidade em oferecer o melhor serviço;

-Capacitação profissional dos colaboradores; -Cortesia e atenção dos colaboradores do terminal.

\section{Confiabilidade}

-Promessa de serviços nos prazos; -Interesse em solucionar problemas; -Comportamento confiável dos colaboradores; -Serviços executados nos prazos; -Registros corretos.

\section{Presteza}

-Esclarecimento de dúvidas;

-Atendimento rápido e eficaz;

-Informações sobre a prestação dos serviços;

-Assistência aos clientes.

Figura 1- Modelo Conceitual Proposto

Fonte: Adaptado de Mattozo et al. 2012

A pesquisa foi realizada através de entrevistas, mediante questionários estruturados que buscaram responder os objetivos do trabalho e à caracterização do perfil do passageiro. A população alvo do estudo foi constituída por passageiros que utilizaram os serviços oferecidos pelo Terminal Rodoviário de Natal (RN), no período de agosto a setembro de 2012, com entrevistas realizadas nas plataformas de embarque do terminal.

O procedimento utilizado para obtenção das amostras necessária para realização da pesquisa foi estruturado através de um plano amostral com um intervalo de confiança de $95 \%$ e margem de erro máxima de sete pontos percentuais (7\%). O cálculo do tamanho da amostra foi definido com base na estimativa da própria população que corresponde a 2.200 (Dois mil e duzentas) pessoas que embarcam mensalmente no Terminal Rodoviário de Natal (RN). 
A amostra foi de 180 (cento e oitenta) questionários, constituindo assim uma amostra representativa da população, para a margem de erro utilizada. Através da técnica de amostragem por conveniência a pesquisadora abordou passageiros que estavam partindo. Os questionários passaram pelos processos de recepção, codificação, digitação e depuração.

Na recepção, os questionários foram contados e verificados seus preenchimentos. Após essa fase, os mesmos foram codificados. Nessa etapa, as opções marcadas pelos pesquisados foram transcritas na parte lateral-esquerda do próprio questionário com o objetivo de facilitar o processo de digitação dos questionários. Na digitação, as informações de cada questionário foram transcritas para o computador e arquivadas em um banco de dados do SPSS Statistical Package for Social Science (SPSS, Inc. 2009).

\section{Resultados}

\subsection{Variáveis de caracterização}

A análise dos resultados foi obtida através de dados que permitiram realizar o tratamento das respostas sobre o perfil dos passageiros, podendo ser caracterizados os indivíduos pesquisados quanto ao estado civil, idade, sexo, grau de escolaridade, ocupação principal, rendimento familiar, cidade e estado de residência fixa. 


\begin{tabular}{|c|c|c|}
\hline Gênero & $\begin{array}{l}\text { Masculino } \\
\text { Feminino }\end{array}$ & $\begin{array}{l}55,00 \% \\
45,00 \%\end{array}$ \\
\hline Faixa Etária & $\begin{array}{l}18 \text { a } 30 \\
31 \text { a } 40\end{array}$ & $\begin{array}{l}39,44 \% \\
22.78 \%\end{array}$ \\
\hline & $\begin{array}{l}41 \text { a } 50 \\
51 \text { a } 60 \\
\text { Acima } 60\end{array}$ & $\begin{array}{r}20,56 \% \\
8,33 \% \\
8,89 \%\end{array}$ \\
\hline Estado Civil & $\begin{array}{l}\text { Solteiro } \\
\text { Casado } \\
\text { Viúvo } \\
\text { Divorciado } \\
\text { Outro }\end{array}$ & $\begin{array}{c}49,44 \% \\
35,56 \% \\
6,11 \% \\
5,00 \% \\
3,89 \%\end{array}$ \\
\hline Grau de Escolaridade & $\begin{array}{l}\text { Ensino Fundamental } \\
\text { Ensino Médio } \\
\text { Ensino Superior Incompleto } \\
\text { Ensino Superior Completo } \\
\text { Outro }\end{array}$ & $\begin{array}{c}13,33 \% \\
46,11 \% \\
22,22 \% \\
15,56 \% \\
2,78 \%\end{array}$ \\
\hline Ocupação Principal & $\begin{array}{l}\text { Funcionário Público } \\
\text { Funcionário de Empresa Privada } \\
\text { Estudante } \\
\text { Aposentado } \\
\text { Outro }\end{array}$ & $\begin{array}{l}13,89 \% \\
36,11 \% \\
24,44 \% \\
13,33 \% \\
12,22 \%\end{array}$ \\
\hline Rendimento Familiar & $\begin{array}{l}\text { Até } \mathrm{R} \$ 1.244,00 \\
\text { De } \mathrm{R} \$ 1.245,00 \text { a } 2.488,00 \\
\text { De } \mathrm{R} \$ 2.489,00 \text { a } 3.732,00 \\
\text { De } \mathrm{R} \$ 3.733,00 \text { a } 4.976,00 \\
\text { Acima de } \mathrm{R} \$ 4.977,00\end{array}$ & $\begin{array}{r}62,78 \% \\
17,78 \% \\
14,44 \% \\
5,00 \% \\
0,00 \%\end{array}$ \\
\hline Cidade & $\begin{array}{l}\text { Natal } \\
\text { Parnamirim } \\
\text { Mossoró } \\
\text { São Paulo } \\
\text { Outras Cidades }\end{array}$ & $\begin{array}{r}35,00 \% \\
5,56 \% \\
5,00 \% \\
3,00 \% \\
51,44 \%\end{array}$ \\
\hline Estado & $\begin{array}{l}\text { Rio Grande do Norte } \\
\text { Paraíba } \\
\text { Pernambuco } \\
\text { Ceará } \\
\text { Outros Estados }\end{array}$ & $\begin{array}{l}79,44 \% \\
3,33 \% \\
2,78 \% \\
2,22 \% \\
12,23 \%\end{array}$ \\
\hline
\end{tabular}

Tabela 1-Perfil do Passageiro do Terminal Rodoviário de Natal

Diante da análise dos resultados obtidos pode-se chegar a um perfil do viajante que embarca na rodoviária de Natal, onde a predominância situou-se em $55 \%$ dos entrevistados eram homens e $45 \%$ eram mulheres. A faixa etária predominante com $39,44 \%$ foi a de 18 a 30 
anos. O estado civil predominou $49,44 \%$ solteiros. O grau de escolaridade com maior representação foi $46,11 \%$ com ensino médio. A principal ocupação foi representada por funcionários de empresa privada com $36,11 \%$. O rendimento familiar com maior evidência situou-se em $62,78 \%$ para o valor de até $\mathrm{R} \$ 1.244,00$. A cidade o estado de origem prevaleceu a cidade de Natal com 35\% das respostas e o Estado do Rio Grande do Norte com 79,44\%.

\subsection{Análise das variáveis relativas ao conteúdo}

As variáveis referentes ao conteúdo da pesquisa, utilizou o modelo SERVPERF, com as seguintes dimensões: Tangibilidade, Confiabilidade, Presteza, Segurança e Empatia.

\begin{tabular}{|c|c|c|c|}
\hline Dimensão & Média & Itens Avaliados por Dimensão & Notas \\
\hline \multirow{4}{*}{ 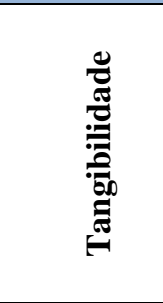 } & \multirow{4}{*}{2,5} & A Rodoviária de Natal tem equipamentos modernos & 2,30 \\
\hline & & $\begin{array}{l}\text { A Rodoviária de Natal oferece instalações físicas atrativas (praça de } \\
\text { alimentação, estacionamento, assentos, iluminação, banheiro). }\end{array}$ & 2,72 \\
\hline & & $\begin{array}{l}\text { Os colaboradores da Rodoviária de Natal têm boa aparência } \\
\text { (Fardamento adequado e limpo). }\end{array}$ & 3,50 \\
\hline & & $\begin{array}{l}\text { A aparência das instalações dos guichês, restaurantes e lojas está } \\
\text { conservada de acordo com os serviços oferecidos. }\end{array}$ & 2,80 \\
\hline \multirow{5}{*}{ 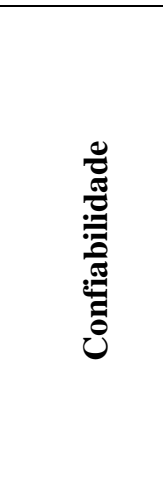 } & \multirow{5}{*}{2,8} & $\begin{array}{l}\text { Os colaboradores da Rodoviária prometem a seus clientes os serviços } \\
\text { nos prazos em que eles serão executados (atendentes dos guichês, } \\
\text { comerciantes e Administração). }\end{array}$ & 3,14 \\
\hline & & $\begin{array}{l}\text { Quando um cliente tem um problema, a Rodoviária demonstra um } \\
\text { sincero interesse em resolvê-lo. }\end{array}$ & 2,47 \\
\hline & & $\begin{array}{l}\text { O comportamento dos colaboradores da Rodoviária inspira confiança } \\
\text { no cliente (atendentes dos guichês, comerciantes e Administração). }\end{array}$ & 3,01 \\
\hline & & A Rodoviária de Natal presta o serviço no tempo prometido. & 3,33 \\
\hline & & $\begin{array}{l}\text { A Rodoviária mantém seus registros de forma correta (horários de } \\
\text { ônibus, destinos, empresas, dados de clientes em passagens). }\end{array}$ & 3,67 \\
\hline \multirow{4}{*}{ 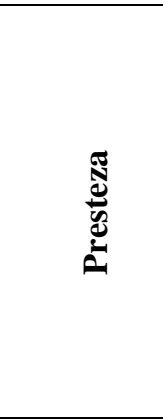 } & \multirow{4}{*}{2,5} & $\begin{array}{l}\text { Os colaboradores da Rodoviária de Natal estão sempre disponíveis } \\
\text { para esclarecer suas dúvidas (atendentes dos guichês, comerciantes e } \\
\text { Administração). }\end{array}$ & 2,57 \\
\hline & & $\begin{array}{l}\text { A Rodoviária de Natal oferece um atendimento rápido aos seus } \\
\text { clientes. }\end{array}$ & 2,96 \\
\hline & & $\begin{array}{l}\text { Os colaboradores da Rodoviária dizem aos clientes exatamente } \\
\text { quando o serviço será prestado. }\end{array}$ & 3,33 \\
\hline & & $\begin{array}{l}\text { Os colaboradores da Rodoviária têm sempre disponibilidade em } \\
\text { ajudar os clientes (atendentes dos guichês, comerciantes e } \\
\text { Administração). }\end{array}$ & 2,63 \\
\hline \multirow{3}{*}{ 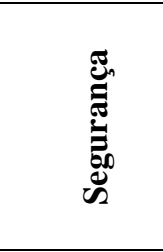 } & \multirow{3}{*}{2,7} & $\begin{array}{l}\text { Você se sente seguro ao utilizar os serviços oferecidos pela } \\
\text { Rodoviária de Natal. }\end{array}$ & 2,80 \\
\hline & & $\begin{array}{l}\text { A Rodoviária está preocupada em oferecer o melhor serviço a seus } \\
\text { clientes. }\end{array}$ & 3,04 \\
\hline & & $\begin{array}{l}\text { Os colaboradores da Rodoviária possuem os conhecimentos } \\
\text { necessários para responder as suas dúvidas (atendentes dos guichês, }\end{array}$ & 3,14 \\
\hline
\end{tabular}




\begin{tabular}{|c|c|c|c|}
\hline & & comerciantes e Administração). & \\
\hline & & $\begin{array}{l}\text { Os colaboradores da Rodoviária são corteses e atenciosos com os } \\
\text { clientes (atendentes dos guichês, comerciantes e Administração). }\end{array}$ & 2,86 \\
\hline \multirow{5}{*}{ 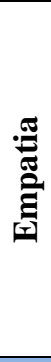 } & \multirow{5}{*}{2,4} & A Rodoviária de Natal lhe dá atenção individual. & 2,26 \\
\hline & & $\begin{array}{l}\text { A Rodoviária tem colaboradores que dão atenção personalizada aos } \\
\text { seus clientes. }\end{array}$ & 2,32 \\
\hline & & A Rodoviária sabe quais são as necessidades de seus clientes. & 2,83 \\
\hline & & $\begin{array}{l}\text { A Rodoviária tem os melhores interesses de seus clientes como } \\
\text { objetivos. }\end{array}$ & 2,65 \\
\hline & & $\begin{array}{l}\text { A Rodoviária tem horários de funcionamento convenientes para seus } \\
\text { clientes. }\end{array}$ & 3,81 \\
\hline & 2,6 & Média de Satisfação Geral & \\
\hline
\end{tabular}

Quadro 1- Comparativo das Dimensões do Modelo Formulado

Fonte: Adaptado Matozzo et al. 2012

$\mathrm{Na}$ avaliação foi utilizada a escala Likert com variação entre 1 e 5 , em que 1 significa discordo totalmente e 5 concordo totalmente, para as afirmações apresentadas. A dimensão Tangibilidade apresentou um valor médio 2,5 o que evidencia uma baixa satisfação dos passageiros. Dentre os itens pesquisados o que obteve um melhor resultado foi o item aparência dos colaboradores do terminal com uma média de 3,5 que afirma que eles estão regularmente satisfeitos e a menor nota foi atribuída à existência de equipamentos modernos no terminal com média 2,3 .

A dimensão Confiabilidade atingiu uma média 2,8, sinalizando uma baixa satisfação dos passageiros. Dentre os itens pesquisados o que obteve um melhor resultado foi o item manutenção de seus registros, com uma média 3,7, afirmando uma aceitação acima da metade da escala, por outro lado, o item interesse dos colaboradores em resolver os problemas de seus clientes representou menor aceitação com média 2,5, atingindo uma média pouco satisfatória.

A dimensão Presteza apresentou um valor médio 2,5 o que corresponde a uma satisfação inferior ao nível médio da escala. O problema existente nessa dimensão ficou evidenciado através da média obtida nos itens disponibilidade dos colaboradores em esclarecer dúvidas e disponibilidade dos mesmos em ajudar os clientes. $\mathrm{O}$ item que correspondeu a uma satisfação moderada encontra-se em informar aos clientes exatamente quando o serviço será prestado, com uma média superior a média da dimensão com 3,3. 
A dimensão Segurança apresentou um valor médio 2,7 o que corresponde a uma baixa satisfação dos passageiros, detectando-se problemas nos itens sentimento de segurança ao utilizar os serviços do terminal e um atendimento cortês e atencioso aos passageiros. Os demais itens obtiveram boa aceitação dos passageiros como conhecimento necessário dos atendentes dos guichês, comerciantes e administração para responder as dúvidas dos clientes com média 3,1 .

A dimensão Empatia apresentou um valor médio 2,4 constatando-se que os passageiros da rodoviária não estão de acordo com a prestação dos serviços no que se refere a cuidados e atenção individual a seus passageiros. Dentre os itens pesquisados o que obteve um melhor desempenho foi quanto ao terminal ter horários de funcionamento convenientes para seus clientes, atingindo uma média 3,8 afirmando sua concordância com o serviço oferecido. O problema sinalizado nessa dimensão corresponde atenção individual aos passageiros.

\section{Considerações Finais}

A competitividade tem feito com que muitas empresas busquem o aprimoramento dos serviços oferecidos aos clientes. Esta é uma realidade em muitas organizações que buscam investir em melhorias, criando assim, uma exigência pela qualidade por parte do consumidor, colocando a qualidade como uma característica fundamental para o sucesso de uma empresa.

A pesquisa buscou analisar a qualidade dos serviços oferecidos pelo Terminal Rodoviário de Natal (RN), identificando os fatores que contribuem para a satisfação dos passageiros que utilizaram os serviços prestados pela rodoviária, através da aplicação do modelo SERVPERF. A satisfação geral foi avaliada através de uma escala de 1 a 5 , sendo definido que os valores iguais ou maiores que 4 representam um elevado nível de satisfação e os inferiores a um nível de satisfação regular.

O resultado da pesquisa evidenciou que as dimensões do modelo proposto de avaliação, contribuem diretamente para a satisfação geral dos passageiros, pois o índice final obtido situa-se em um valor médio de 2,6 pontos como valor médio atingido através do comparativo das cinco dimensões avaliadas, sinalizando que os passageiros não estão satisfeitos com a qualidade dos serviços oferecidos no terminal pesquisado. 
A dimensão Empatia foi a que apresentou maior insatisfação. A causa do problema foi à atenção individual aos passageiros, pois essa dimensão está relacionada à atenção e cuidados individuais aos clientes. A dimensão Tangibilidade teve como causa da insatisfação a inexistência de equipamentos modernos e instalações físicas atrativas. A deficiência da dimensão presteza foi em relação à falta de disponibilidade dos colaboradores em esclarecer as dúvidas dos clientes. Observou-se que na dimensão segurança o atributo que obteve menor aprovação está relacionado à confiança na segurança do serviço e atendimento cortês e atencioso aos passageiros. Por outro lado, verificou-se que na dimensão confiabilidade a discordância foi sinalizada em virtude da falta de demonstração sincera em resolver os problemas dos clientes.

A realização de pesquisas podem avaliar a satisfação e importância das dimensões da qualidade do serviço oferecido na área pesquisada, permitindo quem utiliza o serviço, os passageiros, analisar e auxiliar o gestor no desafio de melhorar a qualidade do serviço em terminais, além de possibilitar o aprimoramento do serviço, como forma de atender as exigências do consumidor.

Contudo, diante dos resultados obtidos por intermédio dos entrevistados que tiveram uma percepção crítica sobre o terminal foi possível identificar que em futuros trabalhos será possível considerar uma análise da satisfação e percepção entre passageiros do estado do Rio Grande do Norte com passageiros residentes em outros estados, podendo trazer resultados significativos em relação ao nível de satisfação em terminais.

\section{Referências}

CRONIN, J. Joseph, Jr. e STEVEN, A. Taylor. SERVPERF Versus SERVQUAL: Reconciling Performance-Based and Perceptions-Minus-Expectations Measurement of Service Quality. Journal of Marketing. Vol. 58. 1992.

GIL, Antônio Carlos. Métodos e Técnicas de Pesquisa Social. São Paulo: Atlas, 2007.

GRÖNROOS, Christian. Marketing: gerenciamento e serviços. Rio de Janeiro: Elsevier, 2009.

KOTLER, Philip; ARMSTRONG, Gary. Princípios de marketing. 7. ed. Rio de Janeiro: Prentice Hall do Brasil, 1998.

. 9. ed.. São Paulo: Prentice Hall do Brasil, 2003b.

LAS CASAS, Alexandre Luzzi. Marketing de serviços. São Paulo: Atlas, 2009. 
LOVELOCK, Christopher; WRIGHT, Lauren. Serviços: marketing e gestão. São Paulo: Saraiva, 2001.

MATTOZO, Teófilo Câmara et. al.. Aplicação Adaptativa do Modelo Fodness e Murray na Avaliação da Satisfação de Passageiros no Aeroporto Internacional Augusto Severo utilizando Regressão Multivariada. Revista Iberoamericana de Turismo, Ritur, Penedo, v. 2, n. 1, p.58-74, 2012.

PARASURAMAN, A.; ZEITHAMI, V.; BERRY, L. et. al. Conceptual Model of Service Quality and its Implications for Future Research. Journal of Marketing, v.49, p.41-50, 1985.

SILVA, José Maria Carvalho da. Dimensões mais relevantes da qualidade percebida por parte dos alunos em serviços prestados por uma instituição de ensino superior: o caso do curso de medicina do UNIFESO. 2009. Dissertação (Mestrado) - Curso de Administração, Universidade Estácio de Sá, Rio de Janeiro.

SILVA, L. M. T.; MEDEIROS, C. A. F. COSTA, B. K. Qualidade dos serviços turísticos no setor de restaurantes: uma aplicação do modelo SERVPERF. Revista Hospitalidade. V. VI, $\mathrm{n}^{\circ}$ 2. ISSN 1807-975X. Dezembro, 2009.

SOUZA, Itamar de. Nova história de Natal. 2. ed. Natal: Atual, 2008. Departamento Estadual de Imprensa.

VERGARA, Sylvia Constant. Projetos e relatórios de pesquisa em administração. 12. ed. São Paulo: Atlas, 2010.

Recebido em: 08/01/2013 ( $1^{\text {a }}$ versão) $30 / 01 / 2013$ ( $2^{a}$ versão)

Aprovado em: 26/09/2013 